\title{
Effects of Sustained Phencyclidine Exposure on Sensorimotor Gating of Startle in Rats
}

\author{
Zoë A. Martinez, M.A., Gaylord D. Ellison, Ph.D, Mark A. Geyer, Ph.D, \\ and Neal R. Swerdlow, M.D., Ph.D
}

\begin{abstract}
Phencyclidine (PCP), a non-competitive NMDA antagonist with actions at multiple other central nervous system receptors, can cause both acute and lasting psychoses in humans, and has also been used in crossspecies models of psychosis. Acute exposure to PCP in rats produces behavioral changes, including a loss of prepulse inhibition (PPI) of the startle reflex, which parallels the loss of PPI observed in schizophrenia patients. Sustained exposure to PCP in rats produces neuropathological changes in several limbic regions and prolonged behavioral abnormalities that may parallel neuropsychological deficits in schizophrenia. It is unclear whether sustained PCP exposure will also produce a loss of prepulse inhibition
\end{abstract}

which parallels the decrease observed in schizophrenia patients. In the present study, we examined changes in PPI during and after sustained PCP administration, using 5-day PCP exposure via subcutaneous osmotic minipumps, or 14-day PCP exposure via repeated intraperitoneal injections. In both forms of drug delivery, PPI was disrupted during, but not after, sustained drug exposure. PPI does not appear to be sensitive to neuropathological effects of sustained PCP exposure.

[Neuropsychopharmacology 21:28-39, 1999]

(C) 1999 American College of Neuropsychopharmacology.

Published by Elsevier Science Inc.
KEY WORDS: Apomorphine; Phencyclidine; Prepulse inhibition; Schizophrenia; Sensorimotor; Startle

Schizophrenia patients demonstrate abnormalities in information processing as measured by deficits in specific behavioral measures. Among these abnormalities, schizophrenia patients exhibit deficient prepulse inhibition (Braff et al. 1978, 1992; Swerdlow et al. 1994). Prepulse inhibition (PPI) is the reduction in startle magnitude that occurs when the startling stimulus is preceded 30-500 msec by a weak stimulus, or "prepulse." A relationship between PPI and clinical symptoms in

From the Department of Psychology (ZAM, GDE), University of California, Los Angeles, California; and Department of Psychiatry (MAG, NRS) UCSD School of Medicine, La Jolla, California.

Address correspondence to: N. R. Swerdlow, Department of Psychiatry, 0804, School of Medicine, University of California, San Diego, 9500 Gilman Drive, La Jolla, CA 92093-0804.

Received August 3, 1998; revised November 24, 1998; accepted December 21, 1998. schizophrenia is demonstrated by the significant correlation between PPI and measures of thought disorder (Perry and Braff 1994) and positive and negative symptoms (Braff et al. 1995) in schizophrenia patients.

PPI can be studied across species and has been shown to be useful in animal studies of sensorimotor gating. In rats, PPI is disrupted by acute treatment with dopamine (DA) agonists (Swerdlow et al. 1986, 1990a,b; Mansbach et al. 1988) or N-methyl-D-aspartate (NMDA) antagonists (Mansbach and Geyer 1989, 1991); the effects of DA agonists can be reversed by typical or atypical antipsychotics, while those of NMDA antagonists are reversed preferentially by clinically atypical antipsychotics (Keith et al. 1991; Swerdlow and Geyer 1993; Hoffman et al. 1993; Swerdlow et al. 1994; Bakshi et al. 1994). In addition, neuroanatomical and neurochemical manipulations in rats within brain circuitry implicated in the neuropathology of schizophrenia also produce these schizophrenia-like PPI deficits (cf. Swerdlow and Geyer 1998). These findings provide insight into neural 
circuit abnormalities that might contribute to the loss of PPI in schizophrenia patients.

PPI deficits in schizophrenia presumably reflect neuronal perturbations that are long-standing, and which may not be modelled optimally by acute and transient drug effects (Sams-Dodd 1998). Although no studies have examined the effects on PPI of sustained or repeated exposure to NMDA antagonists, lasting neuropathological and behavioral effects of prolonged exposure to NMDA antagonists have been reported. For example, neuropathological damage is observed after sustained phencyclidine exposure via subcutaneous minipumps (Ellison and Switzer 1993; Ellison 1994) and lasting behavioral deficits are reported after repeated systemic injections of PCP (Jentsch et al. 1997). In the present studies, we examined the effects of sustained or repeated exposure to PCP on PPI in rats, using the precise methodologies reported by different investigative groups to produce neuropathological damage (Ellison and Switzer 1993; Ellison 1994) and/or significant behavioral abnormalities in rats (Jentsch et al. 1997) that may parallel specific abnormalities in schizophrenia patients.

\section{METHODS}

\section{Rats}

A total of 115 female Sprague-Dawley rats, weighing 225-275 g and 32 male Sprague-Dawley rats (Harlan Laboratories, San Diego, CA), weighing 250-300 g were used in these experiments. Female rats were used for experiments utilizing minipump delivery of $\mathrm{PCP}$, while male rats were used for experiments utilizing repeated $\mathrm{PCP}$ injections, according to the published literature for these two models of sustained and subchronic PCP exposure (Ellison and Switzer 1993; Ellison 1994; Jentsch et al. 1997). Rats were housed in same-sex groups of two or three, except for those with implanted minipumps, which were housed singly, to prevent excessive perturbation of the pumps. A reversed 12-hour light/dark cycle was used (lights on at 1900, off at 0700); surgery and all testing occurred between 1000 and 1700. Rats were handled prior to any procedures to minimize stress during behavioral testing, and were given ad libitum access to food and water except during surgery and behavioral testing.

\section{Drugs}

In studies examining acute drug effects on PPI, saline $(n=$ 8 ) or phencyclidine (PCP HCl) $(0.25,0.75,1.5 \mathrm{mg} / \mathrm{kg}, n=$ 8,8 , and 9 , respectively) was administered subcutaneously (SC) to female rats, and saline or $10 \mathrm{mg} / \mathrm{kg}$ PCP ( $n=16$ per group) was administered intraperitoneally (IP) to male rats. An additional study was conducted to establish a dose-response curve for apomorphine in fe- male rats; in this study, vehicle $(0.01 \%$ ascorbate/saline solution, $n=9)$ or apomorphine $(0.1,0.2,0.4 \mathrm{mg} / \mathrm{kg}$, $n=9,9$, and 8 , respectively) was administered subcutaneously to female rats. In studies examining acute drug effects on animals pre-exposed to sustained administration of PCP, PCP $(0.75 \mathrm{mg} / \mathrm{kg})$ or apomorphine $(0.2$ $\mathrm{mg} / \mathrm{kg}$ ) was administered SC to female rats, based on dose-response effects in naive rats. For sustained administration, osmotic minipumps (Alza Corporation, Palo Alto, CA) filled to deliver $2.73(n=15)$ or $5.45(n=$ 14) $\mathrm{mg}$ /day PCP $\mathrm{HCl}$ were implanted SC under halothane anesthesia. Control rats $(n=18)$ received silastic polymer pellets of approximately the same size and shape as the minipumps (Lipton et al. 1991). For experiments with repeated daily injections, male rats received IP injections of saline or $10 \mathrm{mg} / \mathrm{kg}$ PCP $\mathrm{HCl}$ daily for 14 consecutive days.

\section{Surgery}

Implantation of the subcutaneous minipumps was performed under halothane anesthesia. Rats were initially anesthetized by exposing them to a bell jar containing vaporized halothane. After this, a small area on the back, directly behind the head, was shaved and the rat was placed into a stereotaxic apparatus with a nose cone that delivered a mixture of halothane and air. The area to be incised was cleaned with an alcohol swab, while tail pinch and visual observation of respiratory movements were used to assess sufficient levels of anesthesia. Once the animal was sufficiently and stably anesthetized, a small incision was made with a scalpel, a small subcutaneous pocket was created using blunt dissection, a pump or two pellets were inserted and the incision was closed with wound clips. Explantation involved a similar procedure, with an incision made below the previous incision through which the pump or pellets were removed.

\section{Apparatus}

All experiments utilized four startle chambers (SR-LAB; San Diego Instruments, San Diego, CA) housed in a sound-attenuated room with a $60-\mathrm{dB}$ ambient noise level. Each startle chamber consisted of a plexiglas cylinder $8.2 \mathrm{~cm}$ in diameter resting on a $12.5 \times 25.5 \mathrm{~cm}$ plexiglas stand. Acoustic stimuli and background noise were presented via a Radioshack Supertweeter mounted $24 \mathrm{~cm}$ above the plexiglas cylinder. Startle magnitude was detected and recorded by a microcomputer and interface assembly (San Diego Instruments) as transduced cylinder movement via a piezoelectric device mounted below the plexiglas stand. Startle magnitude was defined as the average of 100 readings collected every 1 $\mathrm{ms}$ beginning at the onset of the acoustic noise burst. Acoustic stimulus intensities and response sensitivities 
were calibrated (using an SR-LAB Startle Calibration System) to be nearly identical in each of the four startle chambers (maximum variability $<1 \%$ of stimulus range and $<5 \%$ of response ranges). Chambers were also balanced across all experimental groups. Sound levels were measured and calibrated with a sound level meter (Quest Electronics, Oconomowoc, WI), A scale (relative to $20 \mu \mathrm{N} / \mathrm{M} 2$ ), with microphone placed inside the plexiglas cylinder. Airpuff stimuli (10 psi, $40 \mathrm{~ms}$ duration) were regulated at the air supply, and were directed $2.0 \mathrm{~cm}$ above the animal's back via a copper tube of $0.5 \mathrm{~cm}$ diameter. The SR-LAB system controlled delivery of acoustic and airpuff stimuli. Methodological details can be found in published material (Geyer and Swerdlow 1998).

\section{Testing Procedures}

Three to seven days prior to testing, all rats were exposed to a brief "matching" startle session. Rats were placed in a startle chamber, (a closed plexiglas cylinder) and exposed to 5 minutes of $70-\mathrm{dB}$ background noise followed by 17 PULSE trials of $40 \mathrm{~ms} 120-\mathrm{dB}$ noise bursts (PULSE ALONE) and 5 PREPULSE + PULSE trials consisting of an 82- $\mathrm{dB}$ (12 $\mathrm{dB}$ above background) prepulse followed $100 \mathrm{~ms}$ by a $120-\mathrm{dB}$ pulse. Data from this session were then used to assign rats to balanced groups according to their average PULSE ALONE startle magnitude.

Behavioral testing began 8-14 days after rat shipment arrival. Rats were brought to the laboratory for 30 minutes and then either treated with vehicle or drug (PCP or apomorphine) 10 minutes prior to a test session (Acute Test) or simply placed into the startle chamber (Sustained Test). Each session was approximately 19 minutes long and consisted of 5 minutes of 70-dB background followed by four trial types: PULSE ALONE noise bursts; and PREPULSE trials which consisted of $20 \mathrm{~ms}$ noise bursts 3,6 , or $12 \mathrm{~dB}$ above 70 - $\mathrm{dB}$ background noise followed $100 \mathrm{~ms}$ by a PULSE. The session consisted of four "blocks": blocks 1 and 4 consisted of four PULSE ALONE trials, and blocks 2 and 3 included both PULSE ALONE (eight trials per block) and 3, 6, and 12 PREPULSE + PULSE trials (five trials each per block), presented in pseudorandom order with a variable inter-trial interval (average of 15 seconds). In addition, interspersed between each stimulus trial, $100 \mathrm{~ms}$ of response was recorded during periods where no stimulus was presented. These trials were called NOSTIM trials and were used to assess gross motor activity during the test session but were not included in the calculation of intertrial intervals. Importantly, while NOSTIM activity can be used as a gross measure of drug "bioactivity," it is not comparable to more sophisticated measures of rat locomotion or stereotyped behaviors. For example, doses of amphetamine that reduce PPI and stimulate locomotor activity have no significant effect on NOSTIM values (Mansbach et al. 1988).

Blocks 1 and 4 were used to calculate acoustic startle reflex habituation (magnitude reduction with repeated stimulus presentations). Although schizophrenia patients exhibit deficits in acoustic startle habituation (Geyer and Braff 1982), tactile (airpuff) startle habituation is more reliably affected by drugs (Geyer and Braff 1982). Hence, immediately upon completion of acoustic startle testing, startle was measured in some rats during exposure to 100 tactile stimuli (10 psi $40 \mathrm{~ms}$ airpuffs; PUFF) with a fixed inter-trial interval of 10 seconds.

\section{TREATMENT AND TEST SCHEDULE}

For a summary of treatments and test schedules, see Table 1.

\section{Experiment 1: Subcutaneous PCP Minipumps}

No published studies have documented the effects of PCP on acoustic startle in female rats. To assess the ef-

Table 1. Treatment and Testing Schedule

\begin{tabular}{|c|c|c|c|c|c|c|}
\hline $\begin{array}{l}\text { Experiment } 1 \\
\text { Group }\end{array}$ & Treatment & Day 1 & Day 3 & Day 5 & Day 15 & Day 16 \\
\hline 2 & $\begin{array}{c}\text { SC PCP injection } \\
\text { (veh, } 0.25,0.75,1.5 \mathrm{mg} / \mathrm{kg} \text { ) } \\
\text { PCP Minipump } \\
(0,2.73,5.45 \mathrm{mg} / \mathrm{d} \text { ) }\end{array}$ & $\begin{array}{c}\text { Test } \\
10 \text { min post-PCP } \\
\text { Pump } \\
\text { implanted }\end{array}$ & Test & $\begin{array}{l}\text { Pump } \\
\text { removed }\end{array}$ & Test & $\begin{array}{l}\text { PCP challenge -Group 2A } \\
\text { APO challenge-Group 2B }\end{array}$ \\
\hline $\begin{array}{l}\text { Experiment } 2 \\
\text { Group }\end{array}$ & Treatment & Day 1 & Day 3 & Day 14 & Day 16 & Days 24/31 \\
\hline 4 & $\begin{array}{l}\text { Daily ip PCP injection } \\
\quad \text { (veh, } 10 \mathrm{mg} / \mathrm{kg} \text { ) } \\
\text { Daily ip PCP injection } \\
\quad \text { (veh, } 10 \mathrm{mg} / \mathrm{kg} \text { ) }\end{array}$ & $\begin{array}{c}\text { Test } \\
10 \text { min post-PCP } \\
\text { Injections } \\
\text { begin }\end{array}$ & $\begin{array}{c}\text { Test } \\
10 \text { min post-PCP } \\
\text { Test } \\
6 \mathrm{~h} \text { post-PCP }\end{array}$ & $\begin{array}{l}\text { Final daily } \\
\text { injection }\end{array}$ & Test & Test \\
\hline
\end{tabular}


fects of subcutaneous PCP administration on the critical behavioral variables, startle and PPI were measured in one group of female rats (Group 1) 10 minutes after SC injection of vehicle or one of three doses of PCP $(0.25$, 0.75 , and $1.5 \mathrm{mg} / \mathrm{kg}$ ). These doses were selected based on published dose-response effects in male rats (Mansbach and Geyer 1989). A second group of rats (Group 2) was tested, 3 days after implantation of subcutaneous osmotic minipumps, to assess the effects of sustained PCP administration on startle, at a time when blood levels of PCP are elevated. Minipumps were removed after the fifth day of PCP exposure. Ten days later, these rats were retested to assess any lasting effects of the 5-day PCP exposure on startle, at a time when neurotoxic effects of such exposure have been observed (Ellison and Switzer 1993; Ellison 1994). Finally, in two "challenge" experiments, PPI was assessed in these rats after treatment with "threshold" doses of either PCP (Group 2A) or the DA agonist apomorphine (Group 2B), to determine whether sustained exposure to PCP increased the sensitivity of the rats to the PPI-disruptive effects of these agents. Some reports suggest that schizophrenia patients exhibit an increased behavioral and neurochemical responsivity to acute challenge with NMDA antagonists (cf. Domino 1964; Lahti et al. 1995a,b).

\section{Experiment 2: Repeated Intraperitoneal PCP Injections}

Startle was assessed in one group (Group 3) of rats 10 minutes after a single IP injection of vehicle or PCP (10 $\mathrm{mg} / \mathrm{kg}$ ), to determine the acute effects of a single IP injection of this dose of PCP on startle. These rats then received daily injections of vehicle or PCP. Startle was reassessed in these rats 10 minutes after their third daily IP injection, to determine the effects of these repeated injections on startle at a time of elevated PCP blood levels. A separate group of rats (Group 4) was given iden- tical daily injections of vehicle or PCP, and was tested 6 hours after their third daily injection, to assess any lasting effects of PCP on startle that might be evident at that time. These rats continued to receive daily injections of either vehicle or PCP $(10 \mathrm{mg} / \mathrm{kg})$ for 14 consecutive days, and startle was assessed 2, 10, and 17 days after cessation of these repeated injections, at times when lasting behavioral and neurochemical effects of repeated PCP injections have been observed (Jentsch et al. 1997).

\section{Data Analysis}

For all ACUTE studies, rats were tested only once. For the SUSTAINED studies, rats remained in only one drug group (e.g., vehicle or PCP) and were tested repeatedly. All data were analyzed using an analysis of variance (ANOVA) with drug treatment as a betweensubject factor and block and trial type as within-subject repeated measures. All post hoc comparisons were conducted using the Tukey-Kramer test. Due to the multiple comparisons pursued in these experiements, alpha was set at 0.01 .

\section{RESULTS}

\section{Experiment 1: PCP Minipumps}

Effects on Startle Magnitude. PCP had no significant effects on startle magnitude in any of the acute or sustained treatment phases (data not shown). For female rats treated acutely with PCP via SC injections (to determine whether PCP reduces PPI in female rats), ANOVA revealed no significant effect of PCP dose on startle magnitude $(F[3,28]=2.83$, ns). On day 3 after minipump implantation, ANOVA revealed no significant effect of PCP dose on startle magnitude $(\mathrm{F}[2,45]<1)$.

PCP acute dose and "challenge"

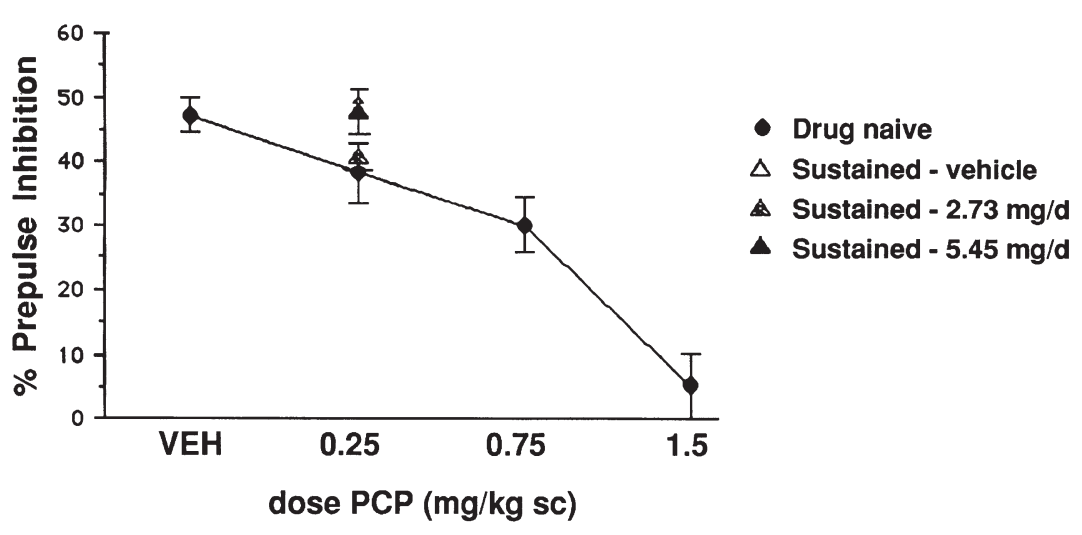

Figure 1. Percent prepulse inhibition, collapsed across all three prepulse intensities $(3,6$, and $12 \mathrm{~dB})$, in drug naive female rats treated with PCP (vehicle, 0.25, 0.75, or 1.5 $\mathrm{mg} / \mathrm{kg} \mathrm{SC}, n=8,8,8$, and 9) and female rats exposed to 5 days of continuous administration of vehicle $(n=9)$ or PCP $(2.73,5.45$ mg/day, $n=8,7)$ administered a subthreshold dose of PCP $(0.25 \mathrm{mg} / \mathrm{kg} \mathrm{SC})$. Error bars indicate SEM. 
Similarly, on day 15 (10 days after minipump removal), ANOVA of startle magnitude revealed no significant effect of PCP dose $(\mathrm{F}[2,45]<1)$. Lastly, on day 16 (11 days after minipump removal), ANOVA of startle magnitude revealed no significant effect of prior PCP dose (i.e., minipump group assignment) in rats challenged with subthreshold doses of PCP $(\mathrm{F}[2,21]<1)$, or apomorphine $(\mathrm{F}[2,21]=2.40, \mathrm{~ns})$.

Effects on PPI. Acute SC administration of PCP in female rats resulted in a dose-dependent reduction in PPI, at doses comparable to those reported to reduce PPI in male rats (Mansbach and Geyer 1989) (Figure 1). No analyses of PPI revealed significant interactions of drug dose $\times$ trial block. For ease of presentation, all data are presented collapsed across Blocks 2 and 3. ANOVA of PPI with dose of PCP as a between-subject factor, and with prepulse intensity as a within-subject factor re-

A.

\section{DAY 3 of Minipump}

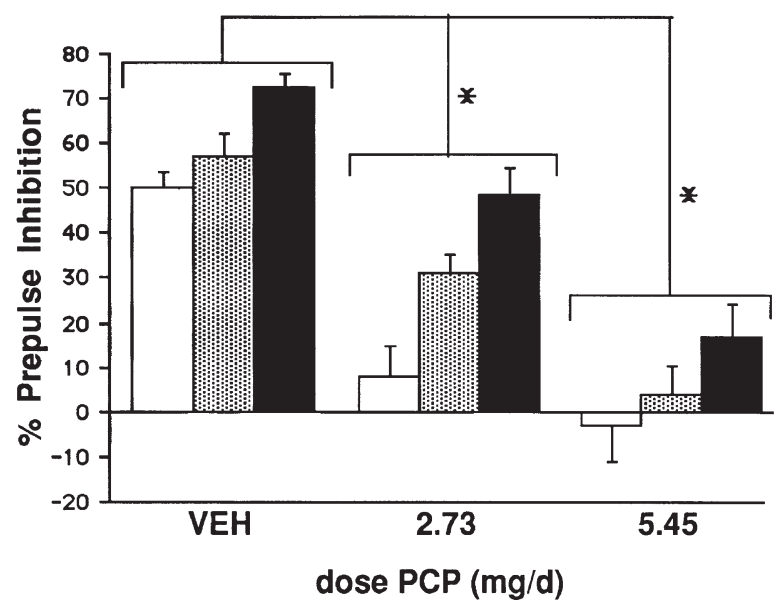

B.

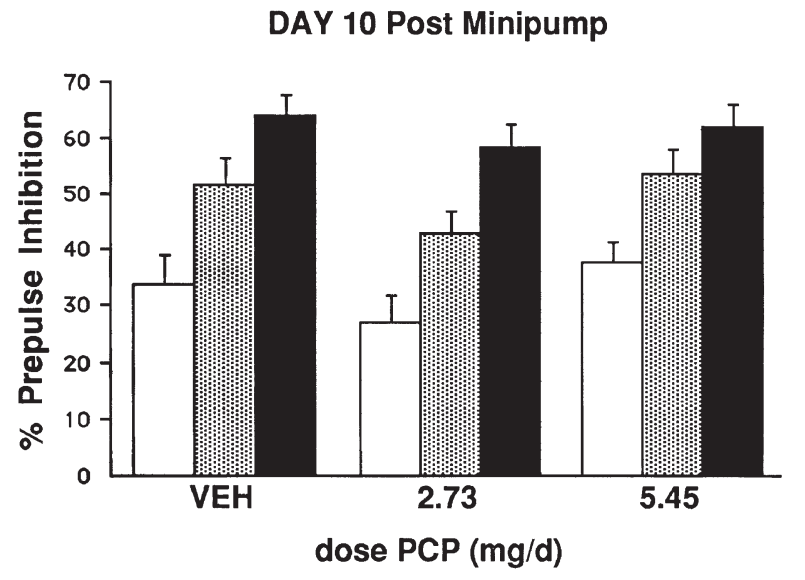

vealed a significant effect of dose $(\mathrm{F}[3,28]=8.38, p<$ $.0004)$ and a significant effect of prepulse intensity $(F[2,56]=35.65, p<.0001)$, but no significant dose $\times$ intensity interaction. Tukey-Kramer comparisons revealed that, compared to vehicle and lower doses of PCP, $1.5 \mathrm{mg} / \mathrm{kg}$ PCP significantly reduced PPI ( $p<.01$, all comparisons). Sustained PCP administration (Figure $2 \mathrm{~A}$ ) via osmotic minipump significantly reduced PPI on day 3 after minipump implantation. ANOVA of PPI with dose of PCP as a between-subject factor, and with prepulse intensity as a within-subject factor revealed a significant effect of PCP dose $(\mathrm{F}[2,45]=26.32, p<.0001)$, a significant effect of prepulse intensity $(\mathrm{F}[2,45]=53.68$, $p<.0001$ ), and a significant dose $\times$ intensity interaction $(\mathrm{F}[4,45]=3.29, p<.02)$. Tukey-Kramer comparisons revealed that both "high"-dose (5.45 mg/day) and "low"dose PCP rats exhibited significantly less PPI compared to saline rats ( $p<.01$ all comparisons).

\section{Prepulse Intensity $(d B(A))$ :}

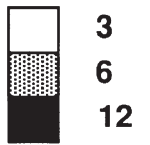

\section{Prepulse Intensity $(\mathrm{dB}(\mathrm{A}))$ :}

Figure 2. (A) Percent prepulse inhibition in female rats treated with PCP for 3 days continuously via implanted subcutaneous pellets (vehicle, $n=18$ ) or minipumps $(2.73,5.45 \mathrm{mg} / \mathrm{d}, n=$ $15,14)$. [* indicates statistically significant reduction of PPI by both low $(2.73 \mathrm{mg} / \mathrm{d})$ and high $(5.45 \mathrm{mg} / \mathrm{d})$ doses of sustained PCP compared to vehicle by Tukey post-hoc analysis $($ alpha $=0.01)$.] (B) Percent prepulse inhibition in female rats 10 days after treatment with PCP for 5 days continuously via implanted subcutaneous pellets (vehicle) or minipumps (2.73, $5.45 \mathrm{mg} / \mathrm{d}$ ). Error bars indicate SEM.

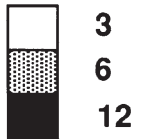


Sustained PCP exposure did not produce lasting PPI deficits (Figure 2B). Rats were tested on day 10 after removal of the minipumps, at which time long-term neuropathological changes have been observed (Ellison and Switzer 1993; Ellison 1994). ANOVA of PPI with PCP dose as a between-subject factor, and prepulse intensity as a within-subject factor revealed no significant effect of PCP dose $(F[2,45]=1.08, n s)$, a significant effect of prepulse intensity $(\mathrm{F}[2,45]=81.87, p<.0001)$, and no significant dose $\times$ intensity interaction $(F[4,45]<1)$.

After sustained exposure to $\mathrm{PCP}$, rats did not exhibit changes in sensitivity to PCP effects on PPI (Figure 1). Half of these rats $(n=24)$ were "challenged" on day 11 after removal of minipumps with a subthreshold dose of PCP $(0.25 \mathrm{mg} / \mathrm{kg}$; based on ACUTE SC administration, Figure 1) to assess whether or not sensitivity to PCP had been altered by sustained treatment. ANOVA of PPI, with previous sustained PCP dose as a betweensubject factor, and with prepulse intensity as a withinsubject factor, revealed no significant effect of previous PCP dose $(F[2,21]<1)$, a significant effect of prepulse intensity $(F[2,21]=72.05, p<.0001)$ and a significant dose $\times$ intensity interaction $(\mathrm{F}[4,21]=3.09, p<.03)$. This significant interaction reflected the fact that, compared to vehicle and high-dose PCP groups, PPI in lowPCP-dose group rats was nonsignificantly reduced for 6- and 12-dB trials, but not for 3-dB trials $(p>.05$, all comparisons). The other half of the rats $(n=23)$ were challenged on day 11 after minipump removal with a subthreshold dose of apomorphine $(0.2 \mathrm{mg} / \mathrm{kg}$; based on ACUTE SC administration, Figure 3) to assess whether or not sensitivity to dopamine receptor-mediated effects of apomorphine on PPI had been altered by sustained treatment with PCP. ANOVA of PPI with previous PCP dose as a between-subject factor, and with prepulse intensity as a within-subject factor, revealed no significant effect of previous PCP dose $(\mathrm{F}[2,21]<1)$, a significant effect of prepulse intensity $(F[2,21]=24.75$, $p<.0001)$ and no significant dose $\times$ intensity interaction $(\mathrm{F}[4,21]<1)$.

Effects on Habituation. Lastly, 10 days after minipump removal, sustained exposure to PCP did not produce long-term effects on startle habituation to repeated acoustic PULSES or to repeated "airpuffs" (Table 2). For acoustic stimuli (Blocks 1 vs. 4), ANOVA of startle magnitude with previous PCP dose as a between-subject factor revealed no significant effect of dose $(\mathrm{F}[2,45]=$ $1.14, \mathrm{~ns})$, a significant effect of trial block $(\mathrm{F}[2,45]=$ 68.24, $p<.0001)$ and no significant dose $\times$ block interaction $(\mathrm{F}[4,45]<1)$. For tactile stimuli $(10$ blocks of 10 trials), ANOVA of startle magnitude revealed no significant effect of previous PCP dose $(\mathrm{F}[2,45]<1)$, a significant effect of block $(\mathrm{F}[9,45]=19.13, p<.0001)$ and no significant dose $\times$ block interaction $(\mathrm{F}[4,45]=1.62$, ns). Lastly, ANOVA of percent change score revealed no treatment effects on reflex habituation (data not shown).

\section{Experiment 2: Repeated PCP Injections}

Effects on Startle Magnitude. To assess a model of subchronic PCP administration (Jentsch et al. 1997), rats were tested at specific time points during and after daily administration of vehicle or $10 \mathrm{mg} / \mathrm{kg}$ PCP IP. Via this route of administration, $\mathrm{PCP}$ had no significant effects on startle magnitude. ANOVA of startle magnitude with PCP dose as a between-subject factor revealed no significant effect of acute PCP $(F[1,14]<1)$. Similarly, ANOVA of startle magnitude with PCP dose as a between-subject factor revealed no significant effects of PCP dose on startle magnitude, when measured on day 3 out of the 14 days of repeated daily injections (either 10 minutes or 6 hours after PCP injection; 10 minutes: $(F[1,6]<1), 6$ hours: $(F[1,14]<1)$, on day 2 after cessation of repeated injections $(\mathrm{F}[1,14]=2.13$, ns), on day 10 after cessation of repeated injections $(\mathrm{F}[1,14]<$

Apomorphine acute dose and "challenge"

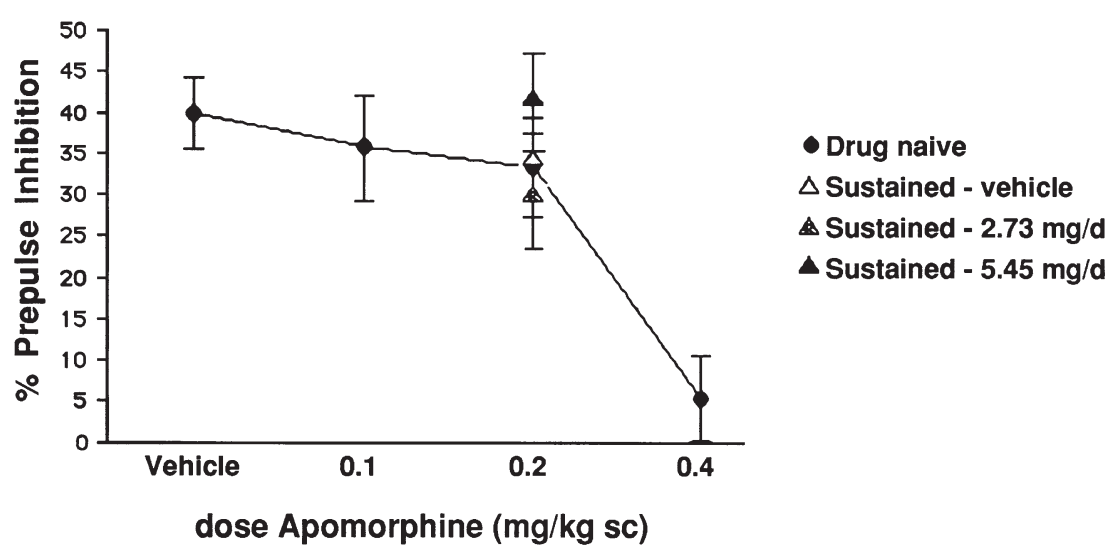

Figure 3. Percent prepulse inhibition, collapsed across all three prepulse intensities $(3,6$, and $12 \mathrm{~dB})$, in drug naive female rats treated with apomorphine (vehicle, $0.1,0.2$, or $0.4 \mathrm{mg} / \mathrm{kg} \mathrm{SC}, n=9$, 9,9 , and 8) and female rats exposed to 5 days of continuous administration of vehicle $(n=9)$ or PCP $(2.73,5.45 \mathrm{mg} /$ day, $\mathrm{n}=7,7)$ administered a subthreshold dose of apomorphine $(0.2 \mathrm{mg} / \mathrm{kg}$ $\mathrm{SC})$. Error bars indicate SEM. 
Table 2. Effects of Sustained PCP Exposure on Startle Magnitude and Habituation (Mean Startle Magnitude (SEM))

\begin{tabular}{|c|c|c|c|c|}
\hline & \multicolumn{2}{|c|}{ Acoustic } & \multicolumn{2}{|c|}{ Tactile } \\
\hline & First Trial Block & Last Trial Block & First Trial Block & Last Trial Block \\
\hline \multicolumn{5}{|l|}{ Experiment 1} \\
\hline $\begin{array}{l}10 \mathrm{~d} \text { post } \\
\text { veh pump }\end{array}$ & 897.64 (124.22) & $343.10(46.10)$ & $502.74(42.36)$ & 333.461 (39.33) \\
\hline $10 \mathrm{~d}$ post & & & & \\
\hline $\begin{array}{l}2.73 \mathrm{mg} / \mathrm{d} \\
\text { PCP pump }\end{array}$ & 701.11 (63.98) & 288.19 (29.35) & $574.31(31.81)$ & $368.40(46.40)$ \\
\hline \multicolumn{5}{|l|}{$10 \mathrm{~d}$ post } \\
\hline $\begin{array}{l}5.45 \mathrm{mg} / \mathrm{d} \\
\text { PCP pump }\end{array}$ & 822.77 (117.96) & 298.25 (20.32) & 501.60 (44.75) & $323.20(39.82)$ \\
\hline \multicolumn{5}{|l|}{ Experiment 2} \\
\hline $\begin{array}{l}2 \mathrm{~d} \text { post daily } \\
\text { veh injections }\end{array}$ & 895.69 (113.37) & $317.50(55.60)$ & & \\
\hline \multicolumn{5}{|l|}{$2 \mathrm{~d}$ post daily } \\
\hline PCP injections & $1198.16(209.48)$ & $572.54(227.51)$ & & \\
\hline \multicolumn{5}{|l|}{$10 \mathrm{~d}$ post daily } \\
\hline \multicolumn{5}{|l|}{$10 \mathrm{~d}$ post daily } \\
\hline PCP injections & 1142.47 (186.51) & 397.69 (93.72) & 489.16 (109.78) & 376.83 (80.18) \\
\hline $\begin{array}{l}17 \mathrm{~d} \text { post daily } \\
\text { veh injections }\end{array}$ & 1040.09 (91.57) & $364.81(66.28)$ & 426.11 (95.98) & $330.45(80.24)$ \\
\hline \multicolumn{5}{|l|}{17 d post daily } \\
\hline PCP injections & 1273.09 (208.24) & 527.94 (149.09) & 490.50 (90.05) & $354.44(77.20)$ \\
\hline
\end{tabular}

1 ), or on day 17 after cessation of repeated injections $(\mathrm{F}[1,14]=2.94, \mathrm{~ns})$ (data not shown).

Effects on PPI. Acute IP administration of PCP significantly decreased PPI on day 1 . ANOVA of PPI with PCP dose as a between-subject factor, and with prepulse intensity as a within-subject factor, revealed a significant effect of PCP $(\mathrm{F}[1,14]=141, p<.0001)$, a significant effect of prepulse intensity $(\mathrm{F}[2,14]=11.90, p<$ .0002) and no significant dose $\times$ intensity interaction $(\mathrm{F}[2,14]=3.04, \mathrm{~ns})$ (Figure 4). As in Experiment 1, no analyses of PPI revealed significant interactions of drug dose $\times$ trial block. For ease of presentation, all data are presented collapsed across Blocks 2 and 3 .

On day 3 of 14 days of repeated injections, PCP significantly decreased PPI 10 minutes, but not 6 hours after IP administration (Figure 5). For rats tested $10 \mathrm{~min}-$ utes after IP PCP injection, ANOVA of PPI with PCP dose as a between-subject factor, and with prepulse intensity as a within-subject factor, revealed a significant effect of PCP $(F[1,6]=33.59, p<.002)$, no significant effect of prepulse intensity $(\mathrm{F}[2,6]<1)$ and no significant dose $\times$ intensity interaction $(F[1,6]=2.31, n s)$. For rats tested 6 hours after IP PCP injection on day 3 out of

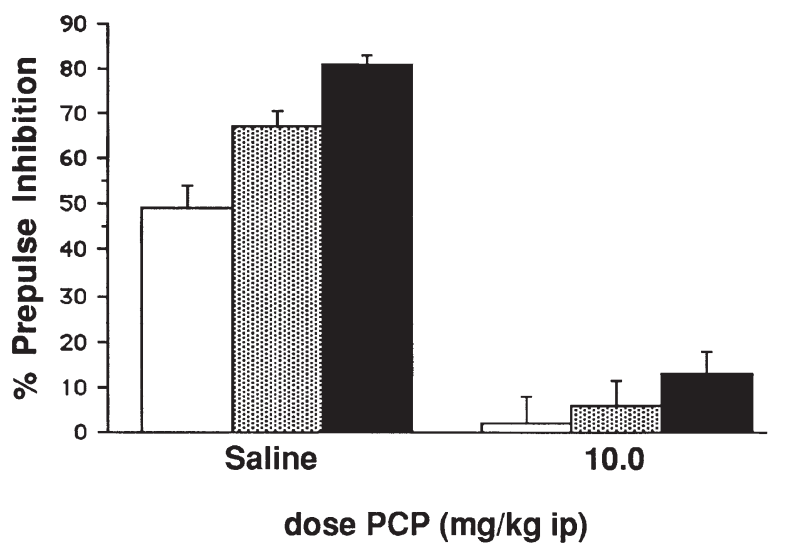

Prepulse
Intensity $(\mathrm{dB}(\mathrm{A}))$ :

3

6

12
Figure 4. Percent prepulse inhibition in male rats treated with PCP (vehicle or 10 $\mathrm{mg} / \mathrm{kg}$ IP). Error bars indicate SEM. 
DAY 3 OF REPEATED INJECTIONS OF PCP (ip)

A. $\mathbf{1 0} \mathrm{min}$ after ip injection

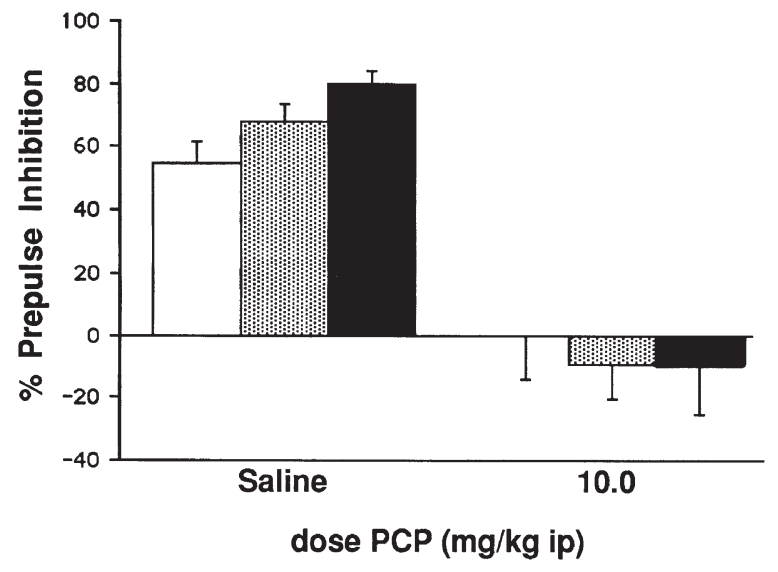

B. $6 \mathrm{~h}$ after ip injection

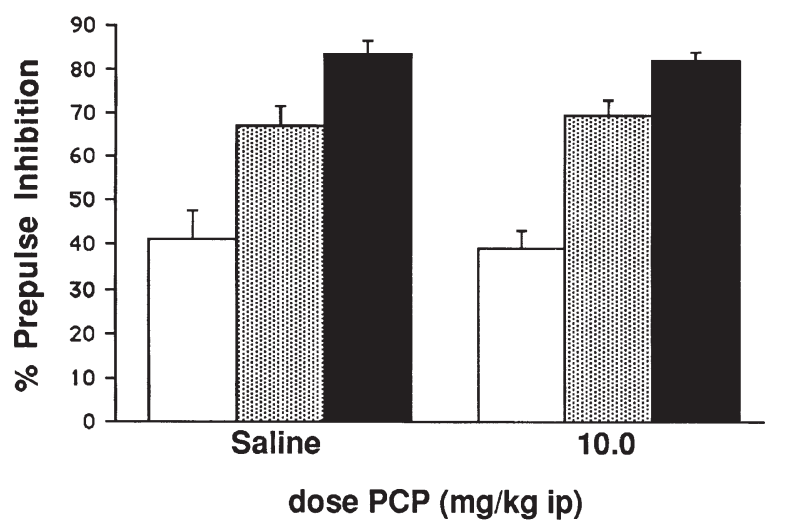

14 days of repeated daily injections, ANOVA of PPI with PCP dose as a between-subject factor, and with prepulse intensity as a within-subject factor, revealed no significant effect of PCP $(\mathrm{F}[1,14]<1)$, a significant effect of prepulse intensity $(\mathrm{F}[2,14]=99.55, p<.0001)$ and no significant dose $\times$ intensity interaction $(\mathrm{F}[2,14]<1)$.

Rats demonstrated no significant effects of PCP on PPI, when tested 2, 10, or 17 days after administration of the last of 14 daily injections of PCP, during a time period reported by others (Jentsch et al. 1997) to be characterized by both neurochemical and "cognitive" changes resulting from repeated PCP administration (Figure 6). For post-PCP day 2, ANOVA of PPI with PCP dose as a between-subject factor, and with prepulse intensity as a within-subject factor, revealed no significant effect of PCP $(F[1,14]=3.32, n s)$, a significant effect of prepulse intensity $(\mathrm{F}[2,14]=39.99, p<.0001)$ and no significant dose $\times$ intensity interaction $(\mathrm{F}[2,14]=1.61, \mathrm{~ns})$ (Figure $6 \mathrm{~A})$. For post-PCP day 10, ANOVA of PPI with PCP
Prepulse Intensity $(\mathrm{dB}(\mathrm{A}))$ :

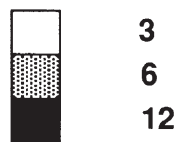

Figure 5. (A) Percent prepulse inhibition in male rats 10 minutes after treatment with PCP (vehicle or 10 $\mathrm{mg} / \mathrm{kg} \mathrm{IP,} n=8$ for both groups) on day 3 of repeated injections of PCP (vehicle or $10 \mathrm{mg} / \mathrm{kg} \mathrm{IP).} \mathrm{(B)} \mathrm{Percent}$ prepulse inhibition in male rats 6 hours after treatment with PCP (vehicle or $10 \mathrm{mg} / \mathrm{kg} \mathrm{IP}, n=8$ for both groups) on day 3 of repeated injections of PCP (vehicle or $10 \mathrm{mg} / \mathrm{kg}$ IP). Error bars indicate SEM.

\section{Prepulse Intensity $(\mathrm{dB}(\mathrm{A}))$ :}

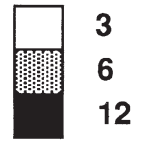

dose as a between-subject factor, and with prepulse intensity as a within-subject factor, revealed no significant effect of PCP $(F[1,14]=1.80, n s)$, a significant effect of prepulse intensity $(\mathrm{F}[2,14]=14.44, p<.0001)$ and no significant dose $\times$ intensity interaction $(\mathrm{F}[2,14]<1)$. For post-PCP day 17, ANOVA with PCP dose as a betweensubject factor, and with prepulse intensity as a withinsubject factor, revealed no significant effect of PCP $(\mathrm{F}[1,14]<1)$, a significant effect of prepulse intensity $(\mathrm{F}[2,14]=68.89, p<.0001)$ and no significant dose $\times$ intensity interaction $(F[2,14]<1)$ (Figures $6 \mathrm{~B}$ and $\mathrm{C}$ ).

Effects on Habituation. Tested 10 or 17 days after exposure to 14 days of daily PCP injections, rats did not demonstrate long-term effects on habituation to repeated acoustic PULSES or to repeated "airpuffs" (day 10) (Table 2). For acoustic stimuli (Blocks 1 vs. 4), ANOVA of startle magnitude with PCP dose as a between-subject factor revealed no significant effects of 
A. 2 days after 14 daily injections

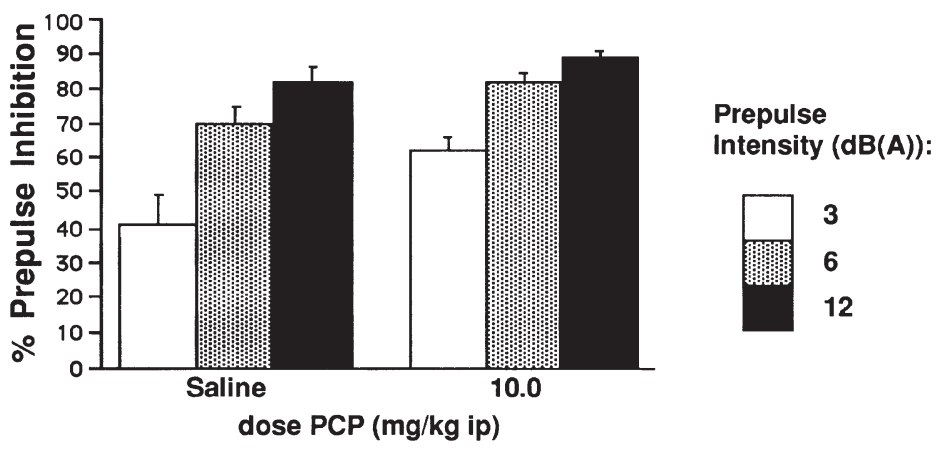

B. 10 days after $14 d$ repeated injections

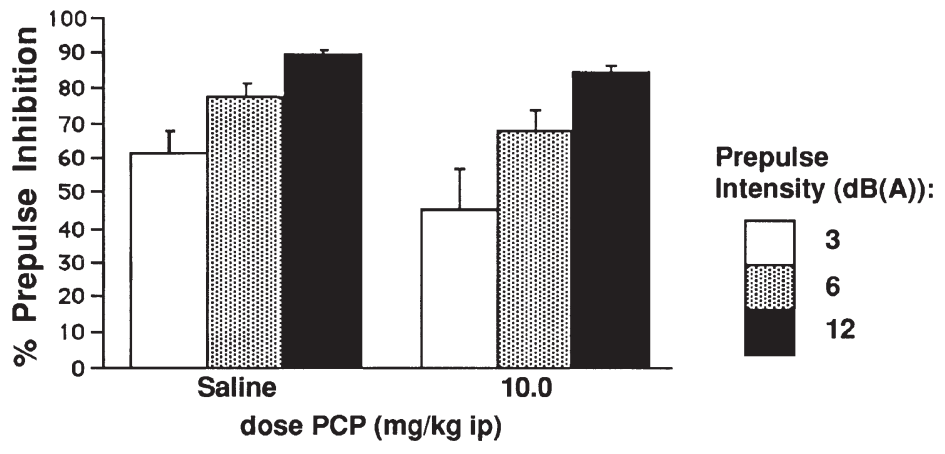

C. 17 days after $14 \mathrm{~d}$ repeated injections

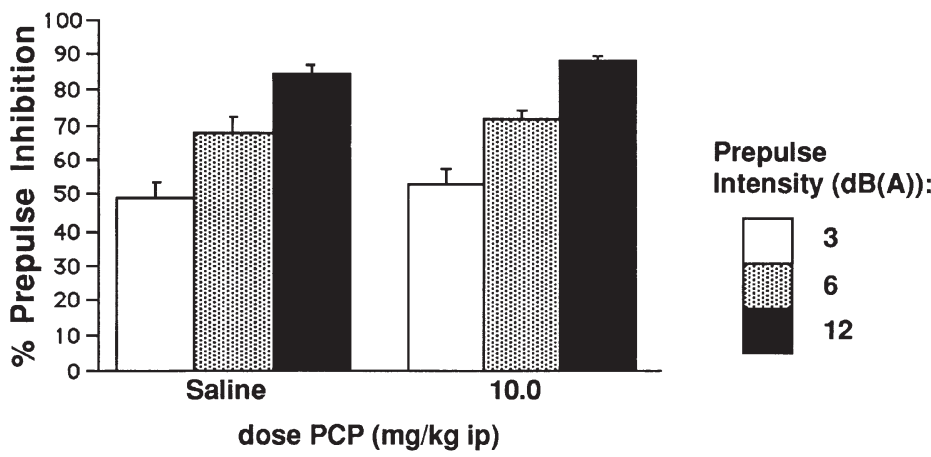

Figure 6. (A) Percent prepulse inhibition in male rats 2 days after 14 daily injections of PCP (vehicle or $10 \mathrm{mg} / \mathrm{kg}$ IP). (B) Percent prepulse inhibition in male rats 10 days after 14 daily injections of PCP (vehicle or $10 \mathrm{mg} / \mathrm{kg}$ IP). (C) Percent prepulse inhibition in male rats 17 days after 14 days of daily injections of PCP (vehicle or $10 \mathrm{mg} / \mathrm{kg} \mathrm{IP).} n=8$ for each group. Error bars indicate SEM.
PCP dose (day 10: $F[1,14]=1.04$, ns; day 17: $F[1,14]=$ 1.46 , ns) and no significant dose $\times$ block interactions (days 10 and 17: F[1,14]<1). For tactile stimuli (10 blocks of 10 trials), ANOVA of startle magnitude revealed no significant effect of PCP dose (day 10: F[1,14] = 2.14, ns; day 17: $F[1,14]<1$ ) and no significant dose $\times$ block interactions (days 10 and 17: F[9,14] < 1) (data not shown). Lastly, as in Experiment 1, ANOVA using a percent change score revealed no significant treatment effects on reflex habituation (data not shown).

\section{DISCUSSION}

The "NMDA Hypothesis" of schizophrenia has been strengthened by reports of the effects of PCP and ket- amine in normal subjects and schizophrenia patients, and of the effects of acute and chronic PCP administration in preclinical models. In humans, acute exposure to PCP or ketamine has been reported to produce both symptoms (e.g., hallucinations and sensory distortions) and cognitive deficits on formal neuropsychological testing, similar to those observed in patients with schizophrenia (cf. Pearlson 1981; Javitt 1987); occasionally, symptoms of PCP "psychosis" can become a lasting condition (Rainey and Crowder 1975; Burns and Lerner 1976; Allen and Young 1978; McCarron et al. 1981; Javitt and Zukin 1991). Acute administration of another NMDA antagonist (ketamine) can produce both "positive" and "negative" schizophrenia-like symptoms in control subjects (Krystal et al. 1994; Malhotra et al. 1996; Breier et al. 1997; Malhotra et al. 1997), and 
can increase glucose metabolism in prefrontal cortex (Breier et al. 1997); similar regional metabolic abnormalities are associated with both schizophrenia symptoms and neuropsychological performance deficits (cf. Frith 1996; Andreasen 1997). Sustained PCP exposure in nonschizophrenic humans who abuse PCP has been associated with lasting neurological and behavioral abnormalities (Fauman and Fauman 1980; Graeven and Sharp 1981) that have been compared to some of the abnormalities seen in schizophrenia patients.

Other observations suggest that schizophrenia patients may also be specifically clinically and neurochemically responsive to NMDA antagonists. Studies of schizophrenia patients exposed to NMDA antagonists have identified ketamine-induced increases in blood flow (rCBF) in anterior cingulate cortex (Lahti et al. 1995a), and an exacerbation of patient-specific symptoms with PCP (cf. Domino 1964) or ketamine (Lahti et al. 1995b).

In rats, acute administration of $\mathrm{PCP}$ produces changes in behavior (Mansbach and Geyer, 1989), neurochemistry (Snell et al. 1988), and brain metabolism (Tamminga et al. 1987; Weissman et al. 1989; Ellison and Keys 1996) that have been used to model pathological processes associated with schizophrenia. Long-standing changes in behavioral and brain measures also result from sustained PCP exposure in rats. Methods of sustained or subchronic PCP administration, via sustained-release osmotic minipumps or repeated daily injections, produce lasting changes in behavior, neurochemistry (Jentsch et al. 1997, 1998), brain metabolism and cell morphology (Ellison and Switzer 1993; Ellison 1994).

Neurochemical changes after repeated daily IP administration of PCP include decreased dopamine utilization in prefrontal cortex (Jentsch et al. 1997, 1998), and these changes are accompanied by behavioral deficits in T-maze alternation (Jentsch et al. 1997) and stress and psychostimulant-induced hyperlocomotion (Jentsch et al. 1998). The neuropathological changes associated with sustained PCP exposure include neuronal degeneration in retrosplenial cortex, posterior cingulate cortex, entorhinal cortex, hippocampus and olfactory regions (Ellison and Switzer 1993; Ellison 1994). Metabolic changes in rats after sustained PCP exposure include elevations in glucose utilization in some of those same areas (Ellison and Keys 1996).

Studies of the neuroanatomy and pharmacology of PPI suggest that it is regulated by brain circuitry that includes the hippocampus, medial prefrontal cortex, nucleus accumbens, basolateral amygdala, striatum, pallidum and pontine tegmentum (cf. Swerdlow and Geyer 1998). Investigations of the specific neuroanatomical substrates for NMDA antagonist effects on PPI have demonstrated that PPI is reduced after infusion of NMDA antagonists into the amygdala (Wan and Swer- dlow 1997; Bakshi and Geyer 1998), the nucleus accumbens (Reijmers et al. 1995), and the dorsal hippocampus (Bakshi and Geyer 1998). It has been suggested that the loss of PPI after systemic administration of NMDA antagonists-as was observed in the present studiesmay reflect the activity of these drugs within multiple brain regions (Bakshi and Geyer 1998).

The present studies were designed to determine whether sustained PCP exposure could reproduce in rats a specific deficit in sensorimotor gating that has been reported in schizophrenia patients (Braff et al. 1978, 1992; Grillon et al. 1992; Bolino et al. 1994). Rats implanted with osmotic minipumps releasing a continuous amount of PCP over a 5-day period exhibited PPI deficits while the minipumps were in place. However, 10 days after removal of the pumps, at a time when significant neuropathological and neurochemical changes have been reported (Ellison and Switzer 1993; Ellison 1994; Ellison and Keys 1996), no significant PCPinduced changes in PPI were evident. On day 3 of a 14 daily repeated-injection paradigm, PCP produced PPI deficits 10 minutes but not 6 hours after injection (i.e., an effect linked with acute but not subchronic PCP effects). In this paradigm, PCP-induced changes in PPI were not observed after cessation of 14 consecutive daily injections, at times when other significant behavioral and neurochemical effects of PCP have been reported (Jentsch et al. 1997, 1998).

While the neurochemical, metabolic, and neuropathological changes caused by sustained and/or subchronic exposure to PCP may certainly model brain processes that are critical to the pathophysiology and cognitive deficits in schizophrenia, the present studies demonstrate that these lasting PCP-induced changes do not cause a lasting functional disturbance in substrates regulating sensorimotor gating in rats. Certainly, this lack of sustained changes in PPI, at times when other behavioral effects of PCP are reported, may reflect a relative insensitivity of PPI to meaningful effects of sustained or subchronic PCP on the brain. To the degree that PPI is regulated by brain substrates responsible for cross-species changes in sensorimotor gating, the present results suggest that the relative loss of sensorimotor gating in schizophrenia does not reflect brain pathology modelled solely by sustained or subchronic PCP exposure.

\section{ACKNOWLEDGMENTS}

This study was supported by MH01436 and MH53484 (NRS), DA02925 (MAG) and DA12841 (GDE). The authors gratefully acknowledge the expert technical assistance of Mr. Erik Randolph, Mr. Navid Taaid, Ms. Pamela Auerbach, and Mr. Jeff Oostwegel. 


\section{REFERENCES}

Andreasen NC (1997): Linking mind and brain in the study of mental illnesses: A project for scientific psychopathology. Science 275:1586-1593

Allen RM, Young SJ (1978): Phencyclidine-induced psychosis. Am J Psychiatry 135:1081-1084

Bakshi VP, Swerdlow NR, Geyer MA (1994): Clozapine antagonizes phencyclidine-induced deficits in sensorimotor gating of the startle response. J Pharmacol Exp Ther 271:787-794

Bakshi VP, Geyer MA (1998): Multiple limbic regions mediate the disruption of prepulse inhibition produced in rats by the noncompetitive NMDA antagonist dizocilpine. J Neurosci 18:8394-8401

Bolino F, Di Michele V, Di Cicco L, Manna V, Danelluzzo E, Casacchia M (1994): Sensorimotor gating and habituation evoked by electrocutaneous stimulation in schizophrenia. Biol Psychiatry 36:670-679

Braff D, Grillon C, Geyer M (1992): Gating and habituation of the startle reflex in schizophrenic patients. Arch Gen Psychiatry 49:206-215

Braff D, Stone C, Callaway E, Geyer MA, Glick ID, Bali L (1978): Prestimulus effects on human startle reflex in normals and schizophrenics. Psychophysiology 15:339343

Braff DL, Swerdlow NR, Geyer MA (1995): Prepulse intensity of the startle response in schizophrenia: The effects of varying prepulse intensity and gender. Proc Amer Coll Neuropsychopharmacology, p 107

Breier A, Malhotra, AK Pinals DA, Weisenfeld NI, Pickar D (1997): Association of ketamine-induced psychosis with focal activation of the prefrontal cortex in healthy volunteers. Am J Psychiatry 154:805-811

Burns RS, Lerner SE (1976): Perspectives: Acute phencyclidine intoxication. Clin Toxicol 9:477-501

Domino EF (1964): Neurobiology of phencyclidine (Sernyl), a drug with an unusual spectrum of pharmacological activity. Int Rev Neurobiol 6:303-347

Ellison G (1994): Neuronal degeneration following both competitive and non-competitive NMDA antagonists. NeuroReport 5:2688-2692

Ellison G, Switzer RC (1993): Dissimilar patterns of degeneration in brain following four different addictive stimulants. NeuroReport 5:17-20

Ellison GD, Keys AS (1996): Persisting changes in brain glucose uptake following neurotoxic doses of phencyclidine which mirror the acute effects of the drug. Psychopharmacology 126:271-274

Fauman M, Fauman B (1980): Chronic phencyclidine (PCP) abuse: A psychiatric perspective. J Psychedelic Drugs 12:307-315

Frith C (1996): Neuropsychology of schizophrenia, what are the implications of intellectual and experiential abnormalities for the neurobiology of schizophrenia? Br Med Bull 52:618-626

Geyer MA, Braff DL (1982): Habituation of the blink reflex in normals and schizophrenic patients. Psychophysiology 19:1-6
Geyer MA, Swerdlow NR (1998): Measurement of startle response, prepulse inhibition, and habituation. In JN Crawley \& P Skolnick (Eds.), Current Protocols in Neuroscience, New York, John Wiley \& Sons, pp 8.7.1-8.7.15

Graeven D, Sharp J (1981): Acute effects of phencyclidine (PCP) on chronic and recreational users. Am J Drug and Alcohol Abuse 8:39-50

Grillon C, Ameli R, Charney DS, Krystal J, Braff D (1992): Startle gating deficits occur across prepulse intensities in schizophrenic patients. Biol Psychiatry 32:939-943

Hoffman DC, Donovan H, Cassella JV (1993): The effects of haloperidol and clozapine on the disruption of sensorimotor gating induced by the noncompetitive glutamate antagonist MK-801. Psychopharmacology 111:339-344

Javitt D (1987): Negative schizophrenic symptomatology and the PCP (phencyclidine) model of schizophrenia. Hillside J Clin Psychiatry 9:12-35

Javitt DC, Zukin SR (1991): Recent advances in the phencyclidine model of schizophrenia. Am J Psychiatry 148: 1301-1308

Jentsch JD, Tran A, Le D, Youngren KD, Roth RH (1997): Subchronic phencyclidine administration reduces mesoprefrontal dopamine utilization and impairs prefrontal cortical-dependent cognition in the rat. Neuropsychopharmacology 17:92-99

Jentsch JD, Taylor JR, Roth RH (1998): Subchronic phencyclidine administration increases mesolimbic dopaminergic system responsivity and augments stress- and psychostimulant-induced hyperlocomotion. Neuropsychopharmacol 19:105-113

Keith VA, Mansbach RS, Geyer MA (1991): Failure of haloperidol to block the effects of phencyclidine and dizocilpine on prepulse inhibition of startle. Biol Psychiatry 30:557-566

Krystal JH, Karper LP, Seibyl JP, Freeman GK, Delaney R, Bremner JD, Heninger GR, Bowers MB Jr, Charney DS (1994): Subanesthetic effects of the noncompetitive NMDA antagonist, ketamine, in humans. Arch Gen Psychiatry 51:199-214

Lahti AC, Holcomb HH, Medoff DR, Tamminga CA (1995a): Ketamine activates psychosis and alters limbic blood flow in schizophrenia. NeuroReport 6:869-872

Lahti AC, Koffel B, LaPorte D, Tamminga CA (1995b): Subanesthetic doses of ketamine stimulate psychosis in schizophrenia. Neuropsychopharmacol 13:9-19

Lipton J, Zeigler S, Wilkins J, Ellison G (1991): A silicone pellet for continuous cocaine: Comparison with continuous amphetamine. Pharmacol Biochem Behav 38:927-930

Malhotra AK, Pinals DA, Weingartner H, Sirocco K, Missar CD, Pickar D, Breier A (1996): NMDA receptor function and human cognition: The effects of ketamine in healthy volunteers. Neuropsychopharmacology 14:301-307

Malhotra AK, Adler CA, Kennison SD, Elman I, Pickar D, Breier A (1997): Clozapine blunts N-methyl-D-aspartatate antagonist induced psychosis: A study with ketamine. Biol Psychiatry 42:664-668

Mansbach RS, Geyer MA (1989): Effects of phencyclidine and phencyclidine biologs on sensorimotor gating in the rat. Neuropsychopharmacol 2:299-308 
Mansbach RS, Geyer MA (1991): Parametric determinants in pre-stimulus modification of acoustic startle: Interaction with ketamine. Psychopharmacology 105:162-168

Mansbach RS, Geyer MA, Braff, DL (1988): Dopaminergic stimulation disrupts sensorimotor gating in the rat. Psychopharmacology 94:507-514

McCarron MM, Schulze BW, Thompson GA, Concer MC, Goetz WA (1981): Acute phencyclidine intoxication: Clinical patterns, complications, and treatment. Annals Emergency Medicine 10:290-297

Pearlson G (1981): Psychiatric and medical syndromes with phencyclidine (PCP) abuse. Johns Hopkins Med J 148:25-33

Perry W, Braff D (1994): Information-processing deficits and thought disorder in schizophrenia. Am J Psychiatry 151: 363-367

Rainey JM, Crowder MK (1975): Prolonged psychosis attributed to phencyclidine: Report of three cases. Am J Psychiatry 132:1076-1078

Reijmers LG, Vanderheyden PM, Peeters BW (1995): Changes in prepulse inhibition after local administration of NMDA receptor ligands in the core regions of the rat nucleus accumbens. Eur J Pharmacol 272:131-138

Sams-Dodd F (1998): A test of predictive validity of animal models of schizophrenia based on phencyclidine and D-amphetamine. Neuropsychopharmacology 18:293-304

Snell L, Yi S, Johnson K (1988): Comparison of the effects of MK-801 and phencyclidine on catecholamine uptake and NMDA-induced norepinephrine release. Eur J Pharmacol 145:223-226

Swerdlow NR, Braff DL, Geyer MA, Koob GF (1986): Central dopamine hyperactivity in rats mimics abnormal acous- tic startle response in schizophrenics. Biol Psychiatry 21:23-33

Swerdlow NR, Braff DL, Masten VL, Geyer MA (1990a): Schizophrenia-like sensorimotor gating abnormalities in rats following dopamine infusion into the nucleus accumbens. Psychopharmacology 101:414-420

Swerdlow NR, Braff DL, Taaid N, Geyer MA (1994): Assessing the validity of an animal model of deficient sensorimotor gating in schizophrenic patients. Arch Gen Psychiatry 51:139-154

Swerdlow NR, Geyer MA (1993): Clozapine and haloperidol in an animal model of sensorimotor gating deficits in schizophrenia. Pharmacol Biochem Behav 44:741-744

Swerdlow NR, Geyer MA (1998): Using an animal model of deficient sensorimotor gating to study the pathophysiology and new treatments of schizophrenia. Schizophrenia Bull 24:285-302

Swerdlow NR, Mansbach RS, Geyer MA, Pulvirenti L, Koob GF, Braff DL (1990b): Amphetamine disruption of prepulse inhibition of acoustic startle is reversed by depletion of mesolimbic dopamine. Psychopharmacology 100:413-416

Tamminga CA, Thaker GK, Buchanan R, Kirkpatrick B, Alphs LD, Chase TN, Carpenter WT (1987): PCPinduced alterations in cerebral glucose utilization in the rat brain: Blockade by metaphit, a PCP-receptor-acylating agent. Synapse 1:497-504

Wan FJ, Swerdlow NR (1997): The basolateral amygdala regulates sensorimotor gating of acoustic startle in the rat. Neuroscience 76:715-724

Weissman A, Marquis K, Moreton J, London E (1989): Effects of self-administered phencyclidine on regional uptake of 2-deoxy-D-[1-14C]glucose in brain. Neuropharmacology 28:575-583 